\title{
Outobiografie as hermeneutiek van die self: Van Rousseau tot Le Clézio
}

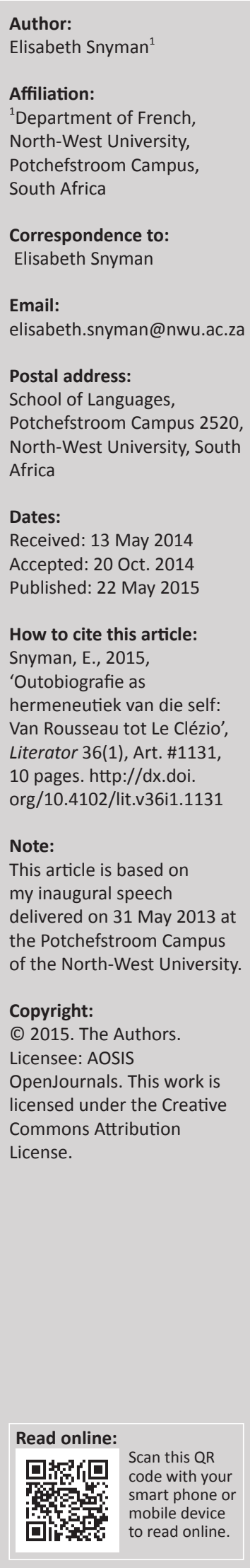

Hierdie artikel ondersoek die hipotese dat outobiografie as 'n soort hermeneutiek van die self beskou kan word. Vir hierdie doel word 'n seleksie van Franse outobiografieë behandel. Aangesien hierdie studie 'n verwerking van 'n intreerede is, is dit oorsigtelik van aard en poog dit nie om 'n gedetailleerde ontleding van óf die teorie óf die tekste waarna verwys word, te gee nie. Jean-Jacques Rousseau se Confessions, wat allerweë as een van die hoekstene van die moderne outobiografie beskou word, is as vertrekpunt gebruik vir die interpretasie van verstaanshandelinge ingebed in outobiografiese tekste. Die artikel toon voorts aan hoe die skrywers van die res van die korpus op verskillende wyses Rousseau se historiese model bevraagteken in aansluiting by nuwer denkwyses. So word daar aangetoon dat George Perec die historiese model laat vaar om eerder tekens uit die verlede te ontsyfer; dat Nathalie Sarraute die gedagte van die verdeelde subjek van die Nuwe Roman kombineer met haar konsep van tropismes om 'n deurleefde weergawe van haar kinderjare te skep; en dat Roland Barthes die aanname dat taal 'n medium van uitdrukking van subjektiwiteit kan wees, problematiseer om 'n 'anti-outobiografie' te skryf. Voorts is aangetoon hoe Marguerite Yourcenar wegbreek van die antropomorfisme van die humanisme om die weg te baan vir die besef dat die teenwoordigheid van die Ander die uitleg van die self ten diepste bepaal. Laastens word die etiek van die Ander in interkulturele ontmoetings, soos geboekstaaf in die outobiografieë van Ken Bugul en Jean-Marie Le Clézio, ondersoek. Die artikel toon aan hoe literêr-filosofiese tendense die gedagte van singewing en interpretasie van die persoonlike verlede en gevolglik die aard van outobiografie vanaf die agtiende eeu beïnvloed het.

Autobiography as hermeneutics of the self, from Rousseau to Le Clézio. This article investigates the hypothesis that autobiography can be regarded as a type of hermeneutics of the self. In order to achieve this, a selection of French autobiographical texts was analysed. As this study is a reworked version of an inaugural lecture, it presents an overview rather than a detailed analysis of the theories or the texts it refers to. Jean-Jacques Rousseau's Confessions, generally regarded as a cornerstone of modern autobiography, was used as a point of departure for the interpretation of operations of understanding at work in autobiographical texts. The article demonstrates how the writers of the rest of the corpus of texts question Rousseau's historical model in different ways according to more recent concepts of the self. Thus it is argued that George Perec replaces the historical model of understanding with an approach based on deciphering signs from the past; that Nathalie Sarraute combines the New Novel's concept of the divided subject with that of tropismes in order to give a truthful representation of her childhood; and that Roland Barthes problematises the notion of language as a medium of expression of subjectivity in his 'anti-outobiography'. This study furthermore demonstrates how Marguerite Yourcenar breaks with the anthropomorphism associated with humanism to pave the way for the realisation that the presence of the Other profoundly determines the understanding of the self. Finally, the ethics of dealing with the Other in intercultural encounters, as recorded in Ken Bugul and Jean-Marie Le Clézio's autobiographies, is examined. The article shows how, from the 18th century onwards, literary and philosophical trends influenced the act of understanding and interpreting the individual existence and hence the nature of autobiography.

\section{Inleiding}

Is 'n outobiografie maar net 'n geskrif oor die wel en weë van 'n lewe waarvan die bruisende jeug ver terug in die verlede lê en waarvan 'n mens hoop om iets op skrif te bewaar teen die dood wat onverbiddelik nadersluip? Of soos Serge Doubrovsky dit tong-in-die-kies stel, "n voorreg gereserveer vir die belangrikes van hierdie wêreld, in die aandskemering van hulle 
lewe en geskryf in 'n mooi styl' (1977)? ${ }^{1}$ Navorsing oor die genre weerlê egter hierdie populêre sienings om die veel meer geskakeerde aard en rol van outobiografie as literêre en kulturele verskynsel uit te lig. Hierdie artikel wil hierby aansluit deur as hipotese te stel dat outobiografie as 'n soort hermeunetiek van die self beskou kan word.

Teoretiese benaderings van outobiografie as genre begin eers na vore kom in die tweede helfte van die twintigste eeu met die opkoms van die narratologie. Dis dan ook in hierdie tyd dat Philippe Lejeune (1975:14) die bekende teoretiese vertrekpunt formuleer dat die skrywer van 'n outobiografie terselfdertyd die verteller en die hoofkarakter van die verhaal is en dat hy 'n soort verdrag met sy leser aangaan waarmee hy die outobiografiese aard van sy teks onderskryf. Hierdie pakt word dan bevestig wanneer die uitgewer op die agterblad van 'n boek die leser inlig dat die betrokke teks die skrywer se lewensverhaal bevat.

Ondanks die klaarblyklikheid van Lejeune se teoretiese omskrywing, ontbreek dit nie aan verdere vrae nie, soos byvoorbeeld of so'n teks werklik'n geloofwaardige weergawe van 'n lewe kan gee. Ons weet immers dat selfs 'n spieëlbeeld nooit eens driedimensioneel kan wees nie, en hoogstens een oomblik in tyd en ruimte kan vasvang. Om dinge verder te kompliseer, is taal as sodanig se verwysingsmoontlikhede vanaf die tweede helfte van die twintigste eeu in die spervuur en hierdie twyfel spoel oor na alle geskrewe genres wat hulle daarop beroep dat hulle na die werklikheid buite die teks verwys, outobiografie inkluis. $\mathrm{Na}$ die sogenaamde talige wending in die filosofie en ander geesteswetenskappe, is daar 'n groter besef van die beperkings van taal as medium vir selfekspressie - soos byvoorbeeld die wete dat 'n teks nooit in 'n een-tot-een verhouding met die werklikheid waarna dit verwys, kan staan nie. Navorsers oor outobiografie aanvaar dat 'n outobiograaf, na aanleiding van sy of haar ervarings, eerder ' $n$ weergawe van hom- of haarself en sy of haar lewe op 'n eiesoortige manier in taal konstrueer as dat hy of sy gebeure bloot presies soos dit gebeur het, oproep. Daar word voorts aangevoer dat dit meer gaan oor die hoe as oor die wat: Die leser leer die skrywer nie alleen ken deur wat hy of sy oor hom- of haarself sê nie, maar juis deur hoe hy of sy hom- of haarself in taal konstitueer (Eakin 1992:67), met ander woorde, deur die talige en literêre konvensies wat gebruik word en ook deur dit wat verswyg word. 'n Siening wat ook steeds sterk figureer, postmodernisme ten spyt, is dat die outobiografiese teks sin probeer maak van die eie verlede (Gusdorf in Lejeune 1971:226). ${ }^{2}$

1. Hierdie aanhaling verskyn op die agterblad van Doubrovsky se boek Fils. (Tensy anders vermeld, is alle vertalings van aanhalings in die artikel deur myself gedoen. Slegs aanhalings langer as 35 woorde word in die oorspronlike taal in voetnote gegee).

2.Die idees van Gusdorf waarna hier verwys word, is oorspronklik in 1956 in Frans gepubliseer in 'n versamelbundel onder die Duitse titel Formen der Selbstdarstellung: Analekten zu einer Geschichte der literarischen Selbstporträts (Reichenkron \& Haase 1956). Vervolgens het Philippe Lejeune Gusdorf se artikel ingesluit in L'autobiographie en France, gepubliseer in 1971. Ongelukkig het Lejeune twee bladsye uitgelaat van die werk sonder om dit aan die leser uit te wys. Omdat twee bladsye uitgelaat van die werk sonder om dit aan die leser uit te wys. Omdat
die oorspronklike kopie van 1956 onverkrygbaar is, gebruik ek dus die weergawe wat in L'autobiographie en France verskyn het vir my verwysings na hierdie werk van Gusdorf, of alternatiewelik, vir die twee ontbrekende bladsye, na die Engelse van Gusdorf, of alternatiewelik, vir die twee ontbrekende bladsye, na die Engelse
vertaling van die teks wat in 1980 in J. Olney se Autobiography: Essays theoretical vertaling van die teks wat in
and critical opgeneem is.

\section{'n Hermeneutiese benadering van outobiografie}

Teen hierdie agtergrond wil ek vanuit 'n hermeneutiese invalshoek die gedagte van outobiografie as singewing en interpretasie van die verlede verder uitdiep. Vir hierdie doel word 'n seleksie van Franse outobiografieë, wat 'n oorsig bied oor 'n paar literêr filosofiese tendense wat die aard van outobiografie vanaf die agtiende eeu beïnvloed het, behandel. Die keuse van die korpus sal soos die argumentasielyn ontvou, verduidelik word.

In aansluiting by Hans-Georg Gadamer en Paul Ricœur se definisies van hermeneutiek poog hierdie artikel om aan te toon hoe die outobiograaf hermeneuties omgaan met die verhaal van sy of haar eie lewe wanneer hy of sy dit retrospektief en selfreflekterend herkonstrueer, probeer verstaan en interpreteer. Gadamer (1975:xviii) se siening dat hermeneutiek nie alleen die uitleg en verstaan van tekste is nie, maar van enige aspek van menslike ervaring is belangrik om my sprong van 'n teks na 'n lewe te regverdig. Ook Ricœur wie se werke so insiggewend vir die narratologie is, praat van 'n hermeneutiese sirkel soortgelyk aan die uitleg van 'n teks wanneer ons die spesifieke handelinge en keuses van ons lewens terugskouend beoordeel in terme van 'n soort Aristoteliese doeleinde (Ricœur 1990:210-211). Om die hermeneutiese uitgangspunt van hierdie studie te verfyn, word Gadamer se definisie van hermeneutiek aangevul deur dié van Ricoeur (1981:43) wat soos volg lui: '[H]ermeneutiek is die teorie van verstaanshandelinge in hul verhouding tot die interpretasie van tekste' en (lyk dit my geoorloof om by te voeg) van 'n lewe.

In Hermeneutics $\mathcal{E}$ the human sciences gee Ricoeur (1981:158) voorts riglyne vir die metodiek van verstaan. Hy onderskei tussen 'verduidelik' en 'interpreteer' waarvan veral die laaste belangrik is vir hierdie studie, want interpreteer hang ten nouste saam met approprieer wat op sy beurt 'n sleutelwoord is vir die beskrywing van die outobiograaf se opskryf van sy of haar lewensverhaal:

Met appropriasie verstaan ek die volgende: dat die interpretasie van ' $n$ teks kulmineer in die selfinterpretasie van 'n subjek wat homself vervolgens beter verstaan, homself anders verstaan of doodeenvoudig begin om homself te verstaan. (Ricoeur $1981: 158)^{3}$

Ricoeur onderstreep vervolgens 'n baie belangrike faset van selfbegrip, 'selfbegrip gaan deur die omweg van die verstaan van kulturele tekens waarin die self homself dokumenteer en vorm gee' (bl. 158).

Die interpretasie van 'n lewe het voorts ook etiese implikasies soos Alasdair MacIntyre (1982:190-209) en veral Paul Ricœur (1990:199-236) aantoon, handelinge word byvoorbeeld goedgekeur of afgekeur in terme van dit waarop so 'n lewe gerig was. Hierdie etiese dimensie sluit aan by 'n tradisie

3.'By appropriation I understand this: that the interpretation of a text culminates in the self-interpretation of a subject who henceforth understands himself better, understands himself differently or simply begins to understand himself'. 
wat teruggaan na die Middeleeue of nog verder terug na Augustinus se De doctrina Christiana, waar hermeneutiek ook die uitleg van allegories mistieke betekenisse in tekste ingesluit het. Ricœur stel onomwonde dat geen vertelling oor die self ooit eties neutraal kan wees nie en dat so 'n teks as die eerste laboratorium vir die slyp van 'n morele oordeel beskou kan word.

My bestudering van spesifieke outobiografieë gaan gevolglik die volgende vrae, ontleen aan die hermeneutiek, as analitiese riglyne gebruik: Eerstens watter vertaanshandelinge gebruik die outobiograaf wanneer hy of sy, sy of haar lewe (as 'teks') interpreteer; tweedens in watter groter geheel word die verhaal van die individuele lewe op dialektiese wyse ingebed; en laastens watter etiese dimensie bevat selfinterpretasie in 'n outobiografie? ${ }^{4}$

\section{Die ontstaan van die outobiografie as afsonderlike genre}

'n Oorsig oor die ontstaansgeskiedenis van die outobiografie bring feite na die oppervlak wat belangrik is vir die hipotese van outobiografie as hermeneutiek van die self. Georges Gusdorf, spoor die verskynsel om oor jouself te skryf, terug tot 26 eeue voor Christus (1980:57-67). Hy toon voorts aan hoe daar later, tydens die vroeg christelike tye - en vanselfsprekend noem hy die Confessiones van Augustinus 'n spesifieke soort bewussyn in die Westerse samelewing ontwikkel wat die ontstaan van die outobiografie voorafgegaan het (in Lejeune 1971:217). Hierdie bewussyn berus op 'n terugskouende selfreflekterende handeling, wat lei na selfondersoek en die belydenis van sondes, vereis deur die Christendom, en wat die praktyk vestig om, soos Augustinus, jou verlede te heroorweeg en om elke handeling in dialoog met God te beoordeel. So 'n belydenis impliseer dat die verborge bronne van die individuele lewe belangrik is, want die aardse bestaan bepaal die mens se ewige lot. Hierdie handeling verplig voorts ook die enkeling om 'n gestileerde en sinvolle weergawe van sy verlede te gee (in Olney 1980:33), wat die weg baan vir die latere outobiografiese vertelling.

Die nuut gevonde subjektiwiteit wat die genre ten grondslag lê, gaan hand aan hand met die ontwikkeling van 'n nuwe historiese bewussyn. Teen die einde van die Middeleeue, aldus Gusdorf (1980:33), neem die Westerse mens afstand van mitologiese verklarings van die lewe om met die Renaissance homself as 'n verantwoordelike agent te begin beskou wat 'n rol kan speel in die verloop van die geskiedenis. So ontstaan die konsep van die 'historiese figuur', wat gedenk word deur die oprig van standbeelde, monumente en tekste wat vandag biografieë genoem word. As gevolg van 'n sameloop van histories kulturele omstandighede, kom daar egter 'n wending in hierdie praktyk so teen die einde van die agtiende eeu, wanneer die skrywers hulle eie lewensgeskiedenisse begin boekstaaf en die gebruik om 'n lewe van buite voor

4.Die etiese dimensie van selfinterpretasie sal spesifiek te berde kom in die bespreking van die tekste van Yourcenar, Bugul en Le Clézio. te stel, aangevul word deur 'n vertelling van die binnelewe van die subjek (Gusdorf 1980:33). Gevolglik word die term 'outobiografie' van die begin van die negentiende eeu af gebruik om dié nuwe selfstandige genre te benoem (May 1979:12). Gusdorf (1980:33) maak gewag van 'n geestelike revolusie - die historikus se voorwerp van ondersoek is nou hom- of haarself en hierdie 'subjek-objek' hoef nie meer 'n belangrike historiese figuur te wees nie.

Dat die verskyning van outobiografie deel uitmaak van 'n groter intellektuele revolusie, word bevestig deur Karl Weintraub (1975):

Outobiografie speel 'n betekenisvolle kulturele rol rondom 1800 n.C. Die groeiende betekenis van outobiografie is dus deel van die groot intellektuele revolusie wat gekenmerk word deur die verskyning van 'n spesifiek moderne vorm van geskiedkundige besef wat ons historisme of historisisme noem. (bl. 821) ${ }^{5}$

In plaas van hom- of haarself hoofsaaklik in terme van 'n universele ideaal te definieer, beskou die individu homof haarself nou as gevorm deur sy eie geskiedenis wat ten nouste bepaal word deur die tyd waarin hy of sy leef (sien Weintraub 1975:829, 833). Hierdie historiese besef loop uit op dit wat ek vir die doel van hierdie studie en in aansluiting by Weintraub, die historiese metode of model van die verstaan van die individuele lewe noem: Die outobiograaf se verhaal van sy of haar lewe toon nou'n duidelike besef dat die verloop daarvan ingekapsel is in ' $n$ wyer historiese konteks. Daar is nie alleen ' $n$ intense bewustheid van hoe die geskiedenis die skrywer se lewe gevorm het nie, maar selfs ook, in sommige gevalle, hoe die individu 'n impak op die geskiedenis van sy of haar tyd gehad het (Weintraub 1975:833).

Sonder dat hy die woord 'hermeneutiek' gebruik, gee Gusdorf op sy beurt reeds te kenne dat die outobiografiese handeling iets veronderstel wat ook 'n wyer impak op die verstaan van die lewe het: Die skryf van 'n outobiografie impliseer 'n tweede lees van die verlede, 'n soeke na selfkennis en sin, 'n lees in die lig van die eie bewussyn (in Lejeune 1971:226). Hierdie hermeneutiese rol van outobiografie word soos volg saamgevat deur Weintraub (1975):

Outobiografie het die literêre vorm geword waarin individualiteit ten beste verreken kon word. Die enigste manier waarop rekenskap gegee kon word van 'n spesifieke persoon, was om sy verhaal te vertel. Selfbewuste kultivering van individualiteit was dieselfde as om in die wêreld te leef met 'n historiese besef (bl. 847). ${ }^{6}$

So loop die eeu van die Verligting dan uit op 'n breuk met die klassieke ideaal van die universele as hermeneutiese konsep om geboorte te gee aan die gedagte dat die individu 'n 'bron van sekerheid is en dat subjektiwiteit die mees voldoende

5.Autobiography assumes a significant cultural function around A.D. 1800. The growing significance of autobiography is thus part of that great intellectual (n) mindedness we call historism or historicism'.

6.'Autobiography ... became the literary form in which individuality could best account for itself. The only way to account for a specific person was to tell its story. Selffor itself. The only way to account for a specific person was to tell its story. Self-
conscious cultivation of individuality was the same as living in the world with historical consciousness.' 
vorm van kennis bied' (Hubier 2003:39). Een van die tekste waarop die bogenoemde opvattings gebaseer is en wat as hoeksteen beskou word van die genre van die outobiografie is die Confessions of te wel 'Belydenisse' (geskryf tussen 1764 en 1770 en postuum gepubliseer) van die bekende Franse skrywer en filosoof, Jean-Jacques Rousseau. Dit is dan ook gepas dat 'n ondersoek na outobiografie as hermeneutiek van die self hierdie epogmakende teks as vertrekpunt sal gebruik.

\section{Jean-Jacques Rousseau: Les Confessions}

Rousseau was nie van adellike geboorte, of enigsins 'n held nie, en tog meen hy dat sy lewe, en wat nuut is, ook sy kinderjare, die moeite werd is om aan ander te vertel. Die inleidingsparagraaf van Rousseau (1952a-c) se Confessions is tekenend van die nuwe subjektiwiteit beskryf deur Gusdorf en Weintraub:

Ek is besig met ' $n$ onderneming waarvan daar geen ander voorbeeld is, of wanneer dit afgehandel is, geen nabootsing sal bestaan nie. Ek wil aan ander' $n$ mens wys in die volle waarheid van sy natuur, en hierdie mens sal ek wees.

Ek alleen. Ek ken my hart en ek ken mense. Ek is nie soos enige ander mens wat ek al gesien het nie; ek waag dit ook om te glo dat ek ook nie gemaak is soos enige ander mens wat bestaan nie. Indien ek nie meer werd is as ander nie, is ek ten minste anders. Of die natuur goed of sleg gedoen het deur die vorm oop te breek waarin ek gegiet is, is iets waaroor mense net kan oordeel nadat hulle my [outobiografie] gelees het. (Rousseau 1952a:9) ${ }^{7}$

Rousseau is egter goed bewus daarvan dat hy in 'n tradisie staan wat deur Augustinus begin is:

Laat die trompet van die laaste oordeel blaas wanneer ook al; ek sal kom en met hierdie boek in die hand verskyn voor die hoogste regter. Ek sal hardop sê: dit is wat ek gedoen het, wat ek gedink het, wat ek was [...]. Ek het myself geteken soos ek was: by tye veragtelik en sleg, dan weer goed, ruimhartig en subliem: ek het my binneste ontbloot soos $U$ dit self gesien het. (Rousseau 1952a:9) ${ }^{8}$

Eers na hierdie metadiskursiewe gedeelte oor die uniekheid van diesubjek en sy projek, maar ook die waarheidsgetrouheid daarvan, kom Rousseau by die gebruiklike 'Ek is gebore in Genève in 1712, seun van ...' (Rousseau 1952a:10) ensovoorts, om dan verder sy lewensverhaal van sy kinderjare af chronologies te vertel.

Die vernuwing van Rousseau se teks lê in die vervanging van die religieuse fokus van Augustinus se Confessiones deur 'n

\footnotetext{
7.'Je forme une entreprise qui n'eut jamais d'exemple et dont l'exécution n'aura poin d'imitateur. Je veux montrer à mes semblables un homme dans toute la vérité de la nature; et cet homme sera moi.

Moi seul. Je sens mon cœur et je connais les hommes. Je ne suis fait comme aucun de ceux que j'ai vus; j'ose croire n'être fait comme aucun de ceux qui existent. Si je ne vaux pas mieux, au moins je suis autre Si la nature a bien ou mal fait de briser

8.'Que la trompette du jugement dernier sonne quand elle voudra; je viendrai, ce livreà la main me présenter devant le souverain juge. Je dirai hautement: voilà ce que j'aifait, ce que j'ai pensé, ce que je fus (...). Je me suis montré tel que je ce que j'aifait, ce que j'ai pense, ce que je fus (...). Je me suis montre tel que je
fus, méprisableet vil quand je l'ai été, bon, généreux, sublime quand je l'ai été: j'ai fus, méprisableet vil quand je l'ai été, bon, génére
}

sekulêre fokus op die individu, wat sy intieme binnewêreld sonder skroom met die leser deel:

Ek het slegs een getroue gids waarop ek kan reken en dit is die ketting van gevoelens wat die opeenvolging van my wese gekenmerk het, en daardeur die ketting van gebeure wat die oorsaak of effek daarvan was'. (Rousseau 1952b:74) ${ }^{9}$

Hierdie klem op innerlike en veral sintuiglike gewaarwordinge, gekombineer met 'n historiese bewussyn, is baie belangrik, want, soos Michael Sheringham (1993:34) aantoon, word Rousseau se outobiografie grotendeels die geskiedenis van sy gevoelens, sintuiglike waarnemings en reaksies op gebeure in sy verlede. Innerlike gevoelens word by Rousseau verhef tot ' $n$ hermeneutiese greep op die verlede waardeur die appropriasie van die eie geskiedenis tot stand kom.

Voorts is Rousseau so seker van die waarheidsgetrouheid van sy teks, en sy outobiografiese projek, dat hy hom, op logosentristiese wyse soos Derrida sou sê, op God as hoogste getuie van hierdie werk se betroubaarheid beroep. Hierdie siening van die self, soos in die agtiende-eeuse outobiografie van Rousseau vergestalt, omvat 'n bepaalde opvatting van die verhouding van die subjek tot taal. Sprinkler (1980:325 verwoord dit soos volg: 'Outobiografie en die konsep van die skrywer se soewereiniteit oor taal is produkte van dieselfde episteem'. Rousseau (1952a:9) twyfel vir geen oomblik daaraan dat die taal wat hy gebruik hom werklik in staat stel om homself te 'teken soos wat [hy] was' nie. Soos ons sal sien, is dit eers later dat hierdie algemeen aanvaarde denkmodel verander en dat die gedagte dat die subjek ondergeskik aan diskoers kan wees, die botoon voer.

Drie aspekte van Rousseau se outobiografie is belangrik vir die argument dat outobiografie 'n soort hermeneutiek van die self is: Die klem op die uniekheid van die self, die geskiedenis of historisiteit van die self as metode om die eie verlede te verstaan, die siening dat taal 'n onproblematiese medium vir die uitdrukking van die eiesoortigheid van die self is en dat so 'n teks gevolglik waarheidsgetrou is. Die daaropvolgende tekste wat ek gaan analiseer is gekies omdat hulle spesifiek een of meer van hierdie aspekte van die eerste moderne Franse outobiografie bevraagteken of dekonstrueer. George Perec se W ou le souvenir d'enfance, die volgende teks wat bespreek gaan word, toon aan dat die historiese metode baie problematies vir die subjek kan wees wanneer hy terugkyk op sy verlede.

\section{George Perec: $W$ ou le souvenir d'enfance ${ }^{10}$}

Die Tweede Wêreldoorlog dien as agtergrond vir Georges Perec se onkonvensionele outobiografie wat eers in 1975, 30 jaar na die oorlog, in sy finale vorm verskyn. Wanneer Perec egter die konvensies uitdaag, is dit nie om kuns ter wille

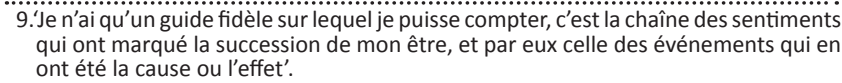
ont été la cause ou l'effet'.

10.In Engels vertaal as W, or the Memory of Childhood (Perec 1988). 
van die kuns nie, maar om met dodelike erns iets van die onsegbare verskrikking van die Jodevervolging weer te gee. Perec is van Pools-Joodse herkoms en verloor beide sy ouers tydens die Tweede Wêreldoorlog. Sy pa sterf nadat hy deur 'n bomskerf getref is en sy ma klaarblyklik op pad van een konsentrasiekamp na 'n ander. Op 6-jarige ouderdom is hy wees en word verder by familie groot. Die outobiografiese deel van die teks begin as volg:

Ek het nie herinneringe aan my kinderjare nie. Tot en met my twaalfde jaar min of meer kan my verhaal in 'n paar reëls opgesom word; ek het my pa verloor op 4, my ma op 6; ek het die oorlog in verskillende tehuise van Villard-de-Lans deurgebring. In 1945 het my pa se suster en haar man my aangeneem. (Perec $1975: 17)^{11}$

Die volwasse skrywer besef egter dat hierdie dun weergawe van sy jeug nie genoegsaam is nie en 'n onbewuste poging mag wees om homself teen sy eie geskiedenis te beskerm. Hy bevraagteken sy aanvanklike stelling 'n paragraaf verder:

'Ek het nie herinneringe aan my kinderjare nie': ek het hierdie stelling met sekerheid gesê, amper uitdagend selfs. Mense moes my nie uitvra oor hierdie saak nie. Dit was nie ingeskryf in my program nie. Ek was daarvan vrygestel: 'n ander geskiedenis, die Grote, Geskiedenis met ' $n$ hoofletter $G$ het reeds in my plek geantwoord: die oorlog, die kampe. (Perec 1975:17) ${ }^{12}$

Dit is belangrik om te noem dat die woord 'Histoire' met 'n hoofletter in die Franse teks gebruik word en dat die woord vir die klank ' $h$ ' in Frans net soos die woord 'byl' in Frans klink. Perec se woordspeling suggereer dus letterlik dat 'Geskiedenis' met sy groot 'byl' in sy plek geantwoord het. Al wil hy ook, soos Rousseau, sy lewe as 'n geskiedkundige proses verstaan, is Perec nie daartoe in staat nie. Die dialektiese bewussyn dat die individuele lewe 'n deel van 'n groter geheel is, vorm by hom 'n paradoksale soort historiese besef: 'Geskiedenis', en meer spesifiek die geskiedenis van die Jodevervolging - 'n gebeurtenis wat ons verstaan van die lewe onherroeplik verander het - het die persoonlike geskiedenis van die individu verswelg en sodoende bepaal. Wat nie eksplisiet in die teks gesê word nie, is dat die skrywer inderwaarheid vir sielkundige terapie moes gaan om agter te kom hoekom hy so min onthou van sy verlede en om sy geheueverlies te oorwin.

Sewe jaar voor die publikasie van $W$ onthou Perec skielik tog iets uit sy verlede, naamlik dat hy op dertienjarige ouderdom 'n verhaal uitgedink het rondom 'n paar van sy eie sketse van atlete in wit klere met 'n hoofletter ' $W$ ' op hulle rûe. Hierdie een enkele jeugfantasie word dan uitgebou tot 'n outobiografie wat op twee parallelle verhale berus. Die een verhaallyn stem ooreen met die konvensie van die

11." "Je n'ai pas de souvenirs d'enfance." Jusqu'à ma douzième année à peu près, mon histoire tient en quelques lignes : j'ai perdu mon père à quatre ans, ma mère à six j'ai passé la guerre dans diverses pensions de Lillard-de-Lans. En 1045, la sœur de mon père et son mari m'adoptèrent.'

12.' "Je n'ai pas de souvenirs d'enfance»: je posais cette affirmation avec assurance, avec presque une sorte de défi. L'on n'avait pas à $m^{\prime}$ interroger sur cette question. Elle n'était pas inscrite à mon programme. J'en étais dispensé : une autre histoire, la Grande, I'Histoire avec sa grande hache, avait déjà répondu à ma place : la guerre, les camps.' outobiografie, maar die fragmentariese inhoud word op 'n onbetrokke manier vertel, die verteller is onseker oor die juistheid van sy herinneringe wat grotendeels opgeroep word deur die bekyk van foto's uit die verlede. Sy soeke word voortdurend ondermyn deur notas wat die volwasse verteller byvoeg en wat die juistheid van dit wat hy onthou, bevraagteken. Die slotsom op 'n eerste vlak van lees is dat daar nie juis veel met hom as kind gebeur het nie. Die ander verhaallyn, waarvan die hoofstukke afgewissel word met die outobiografiese dele, laat die leser se bloed in sy are stol: Dit is die fiktiewe verhaal van 'n eiland waar atlete op die wreedste maniere denkbaar gedwing word om te presteer - 'n perfekte, ongenaakbare sisteem waardeur anonieme mense deur sistematiese onreg gedwing word om te presteer of te sterf. So skep Perec 'n uitgebreide metafoor van die Nazi's se uitwissingkampe waarin sy ma omgekom het. Die onsegbare van die verskrikking van die Jodevervolging en hoe dit die skrywer se lewe geraak het, word gesuggereer deur die wyse waarop hierdie twee verhaallyne op mekaar inspeel en deur verbande wat die leser self moet skep.

Perec se pogings om sy eie amnesie te oorwin word in die teks ingewerk deur die fiktiewe verhaal van 'n karakter wat 'n opdrag kry om na 'n verlore kind te gaan soek en dan agterkom dat hy en die kind dieselfde naam het. Die boek begin met hierdie verhaal, want Perec moet ook 'n verlore kind - hy self - gaan soek en sy ervarings probeer terugroep. Hiermee gee hy moontlik onwetend gehoor aan 'n gesegde wat deur Plato aan Sokrates toegedig word, naamlik "n lewe wat nie ondersoek word nie, is nie die moeite werd om te lewe nie' (sien Kraut 2009:299) - wat, sou 'n mens kon beweer, aan die basis van die outobiografie as genre lê.

Om tog hierin te slaag, verlaat Perec hom op ontsyfering as metode om die verlede na te speur. Hy volg spore en ondersoek merke, wat op hul beurt gestalte vind in inkmerke op papier, spore van skryf wat in die plek kom staan van dit wat nie meer daar is nie:

Ek skryf omdat hulle [my ouers] in my hulle onuitwisbare merk gelaat het en die spoor daarvan is [my] skrywe: die herinnering aan hulle is dood ten tye van [my] skrywe [oor hulle]: [my] skrywe is die herinnering van hulle dood en die bevestiging van my lewe. (Perec 1975:63-64) $)^{13}$

Spore en merktekens van die verlede, wat metafories dui op die hele problematiek van verlies en identiteit (sien ook Sheringham 1993:324) moet ontsyfer en geïnterpreteer word.

Fiksie speel 'n belangrike rol in hierdie ontsyfering van die verlede. Foutiewe herinneringe (soos dié van 'n gebreekte arm) en die hele verhaal van die Olimpiese eiland word metafore wat dui op iets diepers, wat wel waar is - die arm in die verband dui op die verlies van 'n ma en die eiland op die konsentrasiekampe wat onlosmaaklik deel van sy verlede is.

13.[j]'écris parce qu'ils ont laissé en moi leur marque indélébile et que la trace en est leur écriture : leur souvenir est mort à l'écriture ; l'écriture est le souvenir de leur mort et l'affirmation de ma vie.' 
In dieselfde tydperk waarin Perec se outobiografie ontstaan, kom daar ook ander literêre vorme van bevraagtekening van konvensionele vertelwyses na vore, soos byvoorbeeld die Nuwe Roman, wat op sy beurt die konsep van selfrepresentasie ten diepste beïnvloed.

\section{Le Nouveau Roman ${ }^{14}$}

Outobiografie as genre beland in gevaarlike vaarwaters na die Tweede Wêreldoorlog tydens die era van die Nuwe Roman, wanneer ook letterkunde die era van agterdog betree. ${ }^{15}$ Hierdie eksperimentele romanvorm lui 'n soort nuwe realisme in, gebaseer op die fenomenologie, waar die gesitueerdheid in tyd en plek van die subjek, en sy sintuiglike waarnemings die bron word waaruit ' $n$ teks ontstaan. Al die konvensies van die realistiese roman word bevraagteken en doelbewus omver gegooi; die alomteenwoordige verteller word vervang deur ' $n$ subjek wat pretendeer om assosiatief al sy waarnemings hier en nou neer te pen. Tyd, plek, aksie en intrige verloor alle logiese geordendheid en word doelbewus fragmentaries en veelfasettig voorgestel om die kompleksiteit van menslike waarneming na te boots.

In hierdie konteks is outobiografie 'n bietjie verdag - om vanuit jou eie perspektief 'n chronologiese ordening aan jou verlede te gee en sin daarin te soek, en om dit voor te hou as die waarheid, mag baie lyk na 'n terugkeer na die dae toe die Rousseau-subjek nog geglo het dat hy 'n volronde geheel met 'n vaste verwysingspunt was, volkome in beheer van die taal wat hy gebruik om homself mee uit te druk. Vir die Nuwe Romansiers kan ons kennis van die lewe nie meer op die logiese, geordende manier van Balzac en Flaubert se realistiese roman geskied nie, 'n literêre skryfwyse wat vir skrywers soos Alain RobbeGrillet en Roland Barthes in elk geval polities verdag is - dit is by uitnemendheid die romanvorm van die bourgeoisie, meen hierdie avant-garde denkers, waar die klem op die materiële en mag val.

Nogtans pleeg die Nuwe Romansiers outobiografie. RobbeGrillet steek sy tong uit vir die leser wat dink hy gaan hierdie ontwykende skrywer uiteindelik vaspen in sy drieluik outobiografie, natuurlik getiteld Romanesques ${ }^{16}$ en beweer dat alles wat hy tot dusver geskryf het eintlik outobiografies is. Die leser kry in hierdie tekste fragmentariese feite oor RobbeGrillet se lewensverhaal, maar ook, sonder aankondiging, sy fantasieë - hulle is net so deel van hom as dit wat werklik met hom gebeur het, voer hierdie outeur aan. Dat fiksies ook deel kan uitmaak van die verstaan van die self en sy wêreld, 'n gedagte wat reeds by Perec figureer, begin nou sterker op die voorgrond tree. Selfbewussyn strek nou wyer as die mens se rasionele vermoëns wat onlosmaaklik deel is van Descartes se cogito: Die inhoud van die onderbewuste kan ook bydra tot die konstituering van die self.

\section{Die Nuwe Roman.}

15.Ek verwys hier na L'Ère du soupçon, die titel van 'n bundel essays oor die roman, geskryf deur Nathalie Sarraute (1956).

16.Die drie volumes van Romanesques is Le Miroir qui revient (1985), Angélique ou l'enchantement (1988) en Les derniers jours de Corinthe (1994).
Gevorm in hierdie denkklimaat skryf Natalie Sarraute, wat naas Robbe-Grillet en Jean Ricardou gereken word as 'n belangrike teoretikus van die Nuwe Roman, haar outobiografie op die ouderdom van 83 jaar. Sy bly getrou aan die beginsel van tropismes wat al haar werk van 1939 af onderlê, wat enersyds kenmerkend is van die fokus op sintuiglike waarneming van die Nuwe Roman, en andersyds 'n soort hermeneutiese invalshoek op die lewe impliseer. Sy definieer tropismes soos volg:

Tropismes is ondefinieerbare bewegings, wat snel op die grense van ons bewussyn rondgly; hulle lê aan die oorsprong van ons gebare, ons woorde, die gevoelens wat by ons manifesteer, wat ons glo ons ervaar en wat ons [wel] kan definieer. Hierdie tropismes ... lyk my konstitueer die geheime bron ... van ons bestaan. (Sarraute 1956:8) ${ }^{17}$

In ooreensteming hiermee en met die gedagte van die verdeelde subjek van die Nuwe Roman, skep Sarraute in haar outobiografie, Enfance ${ }^{18}$, 'n unieke dialoog tussen haarself en haar dubbelganger, naamlik haar alter ego, wat haar pogings om die verlede te herroep deurentyd bevraagteken:

Wil jy nou regtig dit doen? 'Jou herinneringe aan jou kinderjare oproep'... Hoe pla hierdie woorde jou nie, jy hou nie van hulle nie. Erken nou maar dat dit die enigste woorde is wat jou pas. Jy wil jou 'herinneringe oproep' ... dit help nie om weg te skram nie, dit is so ... (Sarraute 1983:7) ${ }^{19}$

sê die skryfster se dubbelganger, en sy antwoord: 'Ja, ek kan nie anders nie, dit lok my, ek weet nie hoekom nie' (Sarraute 1983:7). Wanneer die heterogene, verglydende elemente op die rand van die bewussyn in die teks in die innerlike dialoog onder woorde gebring word, kom die kompleksiteit van subjektiwiteit met al sy inkonsekwenthede na vore:

Enfance is duidelik' $n$ verlengstuk van Sarraute se fiktiewe werke; wanneer sy fokus op haar eie verlede, behou sy haar bemoeienis met intersubjektiewe ruimte, en met die 'tropistiese' bewegings wat sy net onder die oppervlak van ons alledaagse gedagtes, woorde en gebare waarneem en wat die bestendige identiteite en deurdagte motiewe wat ons meen ons oor beskik, weerspreek. (Sheringham 1993:156) $^{20}$

Hierdie innerlike kruisverhoor, hierdie 'postulering van 'n ander wat aangespreek word' (Sheringham 1993:163) word die hermeneutiese greep waardeur die verteller haar eie 'tropismes' ontsyfer om 'n deurleefde en aangrypende verhaal te skep wat geen eksperiment of doelbewuste polities geïnspireerde spel met konvensies is nie.

17.'Ce sont des mouvements indéfinissables, qui glissent très rapidement aux limites de notre conscience; ils sont à l'origine de nos gestes, de nos paroles, des sentiments que nous manifestons, que nous croyons éprouver et qu'il est possible de définir. Ils me paraissaient encore constituer la source secrète de notre existence'.

18.Die titel kan as 'Kinderjare' vertaal word in Afrikaans.

19.'Alors, tu vas vraiment faire ça? "Évoquer tes souvenirs d'enfance" ... Comme ces mots te gênent, tu ne les aimes pas. Mais reconnais que ce sont les seuls mots qui conviennent. Tu veux "évoquer tes souvenirs" ... il n'y pas à tortiller, c'est bien ça.'

20.'Enfance is clearly an extension of Saraute's fictional work: in turning to her own past, she maintains her concern with intersubjective space, and with the "tropistic" movements she detects just beneath the surface of our everyday thoughts, words, and gestures, movements which give the lie to the settled identities and wellformed motives we like to think we possess.' 
Tydens die tweede fase van die Nuwe Roman word die gedagte van subjektiwiteit (sy dit gefragmenteerd) as bron van kennis, kenmerkend van die eerste fase, ook vaarwel geroep wanneer Jean Ricardou (1971:251) aanvoer dat prosa nie meer gaan oor die skryf van 'n avontuur nie, maar eerder poog om die spoor van die avontuur van skryf te volg. ${ }^{21}$ Tekste word 'n assosiatiewe opeenvolging van metafore wat hulle eie pad loop en die verwysende aard van taal word op die agtergrond geskuif. Hierdie fokus op die avontuur van die teks vind weerklank in Roland Barthes se teoretiese bydraes oor die verwysings(on) moontlikhede van taal wat op hulle beurt weer die hermeneutiese grondslag van sy outobiografie, of te wel anti-outobiografie, vorm.

\section{Roland Barthes: Roland Barthes par Roland Barthes}

In 1975 verskyn Roland Barthes par Roland Barthes ${ }^{22}$ in die reeks monografieë Ecrivains de toujours ${ }^{23}$ wat onmiddellik by die leser die verwagting van 'n outobiografiese teks skep. Maar Barthes spring die leser voor. Op die binnesy van die buiteblad staan die volgende epigraaf: 'Hierdie moet alles beskou word asof gesê deur 'n karakter in 'n roman.' In die teks self verklaar Barthes (1975):

Ek sê nie: 'Ek gaan myself beskryf' nie maar: 'Ek skryf 'n teks, en ek gaan dit R.B. noem' [...] Hoe goed weet ek nie dat daar in die veld van die subjek geen referent is nie? (bl. 60; kursivering deur Barthes

Die boek begin dan met 'n reeks foto's, hoofsaaklik van sy kinderjare en jeug met die skrywer se kommentaar daarby. Dit is sy 'voorgeskiedenis', beweer Barthes, voordat hy 'n skrywer geword het en die 'Teks' oorgeneem het. So neem 'n 'outobiografie' vorm aan wat bestaan uit fragmente waarin die outeur meestal kommentarieer wat hy geskryf het, sy eie denkapparatuur uiteensit of mediteer oor onderwerpe soos taal. Dit is veral die verband tussen die subjek en taal (of die teks) wat Roland Barthes par Roland Barthes van die konvensionele outobiografie onderskei.

Barthes gebruik twee metafore om die komplekse verband tussen taal (die sisteem van betekenaars) en die skrywer (die subjek en referent van die outobiografiese teks) te verduidelik, naamlik die beeld van Medusa en dié van die inkvis. Die Medusa-metafoor is tweeledig: Dit verwys eerstens na die gevaarlike mitologiese figuur met slange vir hare, wat dié een wat reguit na haar kyk, dadelik sou laat versteen. Tweedens, beteken medusa, met 'n kleinletter geskryf, in Frans 'jellievis', 'n organisme wat vassit aan die vel van 'n swemmer en hom brand. Vir Barthes (1975:126) dui 'Méduse' met ' $n$ hoofletter en 'n kleinletter, die taal 'van die Ander' aan, die taal van die massa en massakultuur met sy volle ideologiese lading, wat jou subjektiwiteit verwond as jy

21.Ek verwys hier na Ricardou se bekende werk Pour une théorie du nouveau roman waarin hierdie konsep ' $n$ sentrale argument is.

22.Die titel kan as 'Roland Barthes deur Roland Barthes' in Afrikaans vertaal word.

23.Die titel kan as 'Skrywers van alle tye' in Afrikaans vertaal word. daaraan sou raak. Hierdie taal wat aan almal behoort, kan nooit die diepste gevoelens van die individu oordra nie, meen Barthes. As mens nogtans die indruk het dat daar 'n subjek is wat homself openbaar in 'n teks, is dit slegs "n effek van taal' (Barthes 1975:82).

Teenoor die beeld van die Medusa skep Barthes 'n treffende metafoor wat die skrywer uitbeeld. Die outeur (of die outobiograaf) is soos ' $n$ inkvis wat verdwyn agter die inkwarrels wat hy uitspuit. Die duiker kan raai dat 'n inkvis die bron van die ink moet wees, maar kan hom nie sien nie (bl. 166). Net so kan 'n teks nooit ondubbelslagtig na die skrywer verwys nie - die leser ontmoet slegs maskers in 'n teks (bl. 123), met niemand daaragter nie, aldus Barthes.

Roland Barthes par Roland Barthes illustreer die uitwerking van die sogenaamde talige wending, waarna reeds in die inleiding verwys is, op enige vorm van hermeneutiek. Verstaansmodelle van die wêreld en die lewe kom tot stand deur die filter van taal, maar taal kan nooit eie aan die enkeling wees nie omdat dit aan ' $n$ hele taalgemeenskap behoort. Hierdie gemeengoed kan ook nie deur 'n enkele subjek volkome beheer word nie want talige kodes en beelde, soos byvoorbeeld ideologieë, gevorm deur ander, praat dikwels deur ons sonder dat ons heeltemal daarvan bewus is. Die gevolge hiervan is verreikend en spel die postmoderne krisis van die subjek uit. Rousseau se moderne subjek wat sy eie verhaal in volle vertroue op die verwysingsmoontlike van taal kon vertel, muteer oor tyd om in die tweede helfte van die twintigste eeu ' $n$ gedestabiliseerde, gefragmenteerde subjek te word, wie se medium van uitdrukking nie sonder meer deursigtig is nie is.

Hierdie 'krisis van die subjek' word ietwat anders benader deur die gevierde skryfster Marguerite Yourcenar, tydgenoot van Barthes, wat nadat sy beroemdheid verwerf het in die sewentigerjare, begin werk aan 'n drieluik outobiografie getiteld Le Labyrinthe du Monde (Yourcenar 1991b). ${ }^{24}$

\section{Marguerite Yourcenar: Le Labyrinthe du Monde ${ }^{25}$}

Soos Barthes, is Yourcenar bewus van die beperkinge van taal, en die moontlike fragmentasie van die subjek, maar haar werk bly grotendeels getrou aan 'n modernistiese perspektief op die lewe, in die sin dat die aard van identiteit en die grense van die subjek bevraagteken word, maar nog nie lei tot die disintegrasie van die subjek nie.

'n Welbekende outobiografiese konvensie, naamlik die portret van die ouers van die outeur, lê aan die basis van die eerste

24.Vir alle verwysings in hierdie studie na die drie volumes van Yourcenar se outobiografie met die oorkoepelende titel Le Labyrinthe du Monde, word die tweede volume van haar versamelde werke gebruik, uitgegee in 1991 onder die titel Essais et Mémoires deur Gallimard in die Pléiade-reeks. Die drie volumes van titel Essais et Mémoires deur Gallimard in die Pléiade-reeks. Die drie volumes van
Le Labyrinthe du Monde het elk sy eie titel: Souvenirs Pieux, Archives du Nord en Quoi l'éternité. Die volumes van die trilogie is reeds voorheen afsonderlik onder hulle eie titels gepubliseer, soos ek in die loop van die artikel sal aandui. 
twee volumes van hierdie teks. Wat nuut is, is dat Yourcenar hierdie konvensie uitbrei na twee volle boeke, waarvan die eerste gewy word aan die genealogie van haar moeder se voorsate en 'n uitbeelding van 'n ma wat sy nooit geken het nie (sy is oorlede tien dae na die skryfster se geboorte). Hierdie eerste poging tot ' $n$ hermeneutiek van die self sluit aan by die historiese metode en lê baie klem op die gedagte dat die enkeling die produk is van 'n lang lyn voorsate of van mense met wie sy 'n besondere affiniteit voel. Die historiese model word egter heeltemal oorskadu deur veel minder rasionele maniere van die verlede interpreteer. Hiervan getuig die epigraaf van die eerste volume Souvenirs Pieux ${ }^{26}$ (oorspronklik gepubliseer in 1975), wat die vorm aanneem van 'n raaisel: 'Hoe het jou gesig gelyk voordat jou ouers mekaar ontmoet het?' (Yourcenar 1991b:705). Hierdie uitdrukking is 'n sogenaamde kōan zen, 'n raaisel wat sy oorsprong in die Zen-Boeddhisme het. Die kōan zen het oorspronklik deel uitgemaak van die opleiding van boeddhistiese monnike en het ten doel om die leerling 'n waarheid te laat ontdek wat hy onbewustelik reeds weet (Lenoir \& Masquelier 1997:1116). Yourcenar suggereer dus dat by die lees van Le Labyrinthe $d u$ Monde, die leser gekonfronteer gaan word met bepaalde vrae, maar die antwoorde sal nie maklik te vinde wees nie. Soos 'n student van die Boeddhisme, sal die leser dalk ook op ander vermoëns as net sy rede moet staat maak om 'n antwoord te vind op die raaisel wat aan die begin van die volume gestel word. Yourcenar nooi ons uit om intuitief na te dink oor die enigma van identiteit, sy dit dié van elke mens, of dié van die outobiograaf.

Die tweede volume, Archives du Nord ${ }^{27}$ (oorspronklik uitgegee in 1977), maak 'n draai by die skepping, om die geografiese vorming van die streek waar haar vader se eerste voorsate sou woon, te verken. Nadenke oor die vernietigende uitwerking van die mens se teenwoordigheid op die natuur lui hierdie geskiedenis in en so word dit algaande duidelik dat wanneer die skryfster oor haar vader se genealogie praat, het sy dit ook - en nogal op 'n besonder negatiewe wyse oor die mens in die algemeen. In die derde en laaste volume van Le Labyrinthe du Monde (Quoi? L'Éternité, postuum gepubliseer in 1988) rekonstrueer Yourcenar haar vader se lewe na haar eie geboorte en vertel sy ook die verhaal van 'n egpaar wie se bestaan nou verweef was met haar en haar vader se lewens. Haar eie kinderjare en adolessensie word baie kortliks behandel in sowat 20 bladsye. Kan 'n mens nog praat van 'n outobiografie as die subjek so afwesig is? Tog vind selfrepresentasie plaas op 'n onkonvensionele en indirekte wyse, want Marguerite Yourcenar openbaar haarself in die manier waarop sy oor ander mense skryf. Die seleksie van feite, die kommentaar van die verteller oor die lewens van ander, haar identifisering met sommige en verwerping van ander, die literêre stilering van die verlede sowel as die fiktiewe gedeeltes, skep onmiskenbaar ' $n$ beeld van die skryfster en verteller. Haar selfbewussyn neem geleidelik vorm aan soos sy haar posisioneer ten opsigte

26.Die titel sou as 'Vrome herinneringe' in Afrikaans vertaal kon word.

27. Die titel beteken letterlik 'Argiewe van die Noorde'. Yourcenar self het die titel How many years (uitgegee in 1995) vir die Engelse vertaling van die werk gekies. van denkrigtings van die twintigste eeu, wat sy nooit volkome haar eie maak nie. Haar nadenke oor en verstaan van haar menswees breek met die antropomorfisme van die humanisme en die konvensionele outobiografie, sluit aan by 'n boeddhistiese geringskatting van menslike individualiteit en bevraagteken die koherensie van die subjek op 'n manier wat tog herinner aan sekere postmoderne sienings. Algaande vorm 'n selfportret wat 'n sentrale plek aan haar rol as skrywer toeken. Dat haar skrywerskap 'n baie belangrike faset van haar identiteit is, word ook bevestig deur die wyse waarop sy haarself voorstel aan die gehoor tydens haar intreerede in tot die Franse Akademie:

Hierdie onsekere en drywende ek, hierdie entiteit waarvan ek die bestaan self bevraagteken het en wat ek voel slegs afgebaken kan word deur die paar werke wat ek geskryf het, hier is sy. (Yourcenar 1981:10)

Anders as haar voorgangers beklemtoon Yourcenar deurgaans die nietigheid van die individu en hou vol dat sy net ' $n$ mens soos enige iemand anders is. In stede daarvan om op die uniekheid van Marguerite Yourcenar te konsentreer, maak haar outobiografie die leser bewus van nypende eksistensiële probleme van die twintigste eeu, soos die ekologie en die sinlose vernietiging wat oorloë meebring.

Dit is juis hierdie middelpuntvliedende aard van Le Labyrinthe $d u$ monde wat ' $n$ besondere vorm van hermeneutiek van die self omvat, 'n hermeunetiek wat 'n belangrike plek aan etiese besinning en die 'Ander' toeken en suggereer dat subjektiwiteit nie meer 'n onweerlegbare bron van kennis kan wees nie. Yourcenar se outobiografie breek met antropomorfisme om alle vorme van lewe, alles wat 'anders' as die self is, in te sluit. Die uiters beperkte ruimte wat haar eie persoonlike geskiedenis inneem in hierdie drie volumes is tekenend van haar slagspreuk -'die weinig wat ons is' (Yourcenar 1991b:806) - en sluit aan by die kernboodskap van haar teks, naamlik 'n oproep tot die bewaring van die natuur en alle vorme van lewe. Hierdie etiese inhoud van die vertellersdiskoers, lei op logiese wyse na die raakpunt wat Anne-Yvonne Julien (2002) uitwys tussen Yourcenar se œuvre en dié van Paul Ricœur. Soos Ricoeur, maak Youcenar (1981):

$[V]$ an die vertelling net soveel as van die verlede, 'n verpligte weg na die bewuswording van die self, wat terselfdertyd kennis en konstruksie is, en wat uitloop op die opneem van etiese verantwoordelikheid. (bl. 236)

In die laaste instansie wil hierdie artikel aandag gee aan nog ' $n$ manier waarop die hermeneutiese handeling van die outobiografiese teks ons die geleentheid gee om, in die woorde van Emmanuel Levinas, die gelaat van die 'Ander' te ontmoet met al die etiese en die politieke konnotasies daaraan verbonde.

\section{Outobiografie en interkulturaliteit}

Die tema van interkulturaliteit beklee 'n belangrike plek in ' $n$ multidissiplinêre debat oor alteriteit, emigrasie en/of 
immigrasie en gasvryheid ${ }^{28}$ wat oor die laaste twee dekades na vore kom en die vraag laat ontstaan of die weergawe van die subjek se ontmoeting met ander kulture in outobiografieë nuwe verstaanshandelinge blootlê.

Hierdie kwessie is veelfasettig: Magsverhoudinge (soos deur onder andere Foucault gedefinieer) speel dikwels 'n baie belangrike rol in hierdie outobiografieë, asook 'n postkoloniale bewussyn van gesitueerdheid wat oorheers in die outobiografieë van Franstalige Afrikaskrywers. In hierdie tekste kom daar 'n etiese dimensie na vore wat die hermeneutiek van die self anders maak as dié van Rousseau se strewe om die unieke self uit te beeld of Yourcenar se oproep tot respek vir alle vorme van lewe.

Vir die doel van my ondersoek het ek die volgende twee outobiografiese tekste gekies, naamlik Le Baobab fou ${ }^{29}$ ([1982] 1996) van die Senegalese skryfster Ken Bugul (die skuilnaam van Mariétou M'bay) en L'Africain ${ }^{30}$ (2004) van Jean-Marie Le Clézio, die Franse Nobelpryswenner van 2008. Hierdie spesifieke tekste belig die hermeneutiek van die self in 'n interkulturele konteks op uiteenlopende wyses wat nuwe perspektiewe open wanneer hulle saam beoordeel word. Bugul se teks is gebaseer op die skryfster se eerste ervaring van die Europese kultuur tydens 'n studieverblyf as beurshouer in België. Le Baobab fou verwoord die totale ontworteling van die self, die gevolg van die skok van die interkulturele ontmoeting. Le Clézio, daarenteen, berig hoe 'n verblyf in Afrika as kind vir hom nuwe ankers gee wat sy hele œuvre sou beïnvloed. Beide skrywers beoordeel hulle eie individuele verlede in die lig van die groter konteks van die kolonialisasie van Afrika.

Bugul vertel hoe sy as student in België vir die eerste keer besef dat sy swart is. Ver van die tradisies van landelike Afrika, waarvan sy 'n soort mitiese, geïdealiseerde voorstelling gee, verloor sy haar identiteit en beland in 'n spiraal van morele verval. Die belang van die teks lê in die illustrasie wat dit bied van die teoretikus Homi Bhabha ([1994] 2003:1) se 'tussen-in ruimtes' of 'oomblikke of prosesse wat ontstaan in die artikulasie van kultuurverskille'. Hierdie oomblikke bied volgens Bhabha die geleentheid vir die 'uitwerk van strategieë van die self', wat nuwe kenmerke van identiteit kan inisieer, wat ook deur bevraagtekening en samewerking die konsep van 'n samelewing innoverend kan help definieer. Bhabha ([1994] 2003:2) gee egter toe dat sulke tussenruimtes ondanks hulle kreatiewe potensiaal, ook gekenmerk kan wees deur konflik en antagonisme.

En dit is juis woede oor die effek van kolonialisasie op Afrika wat Ken Bugul se nadenke oor haar verblyf in België en haar poging om haar ervarings te interpreteer, kenmerk. Dit blyk onmoontlik vir die individu te wees om die mag

28.Sien byvoorbeeld Julia Kristeva se Étrangers à nous-mêmes (1991); Jacques Derrida en A. Dufourmantelle se essay: De l'Hospitalité (1997) en Emmanuel Levinas se Totalité et Infini. Essai sur l'extériorité (1961).

29.Die boek is in Engels vertaal as The Abandoned Baobab (Bugul 1991).

30.Die boek is in Afrikaans vertaal as Die Afrikaan (Le Clézio 2010). van stereotipes te deurbreek en 'n gevoel van mislukking oorheers. Die groter konteks van koloniale magsverhoudinge tussen die Weste en Afrika, en die gevolge daarvan op postkoloniale Afrika, oorheers die hermeneutiek van die self. Die implikasie is dat Ken se lewe onherroeplik deur kolonialisasie en die nawerking daarvan gedetermineer is. Dit is eers wanneer Ken na haar verblyf in Europa as skryfster ontluik dat die tussenruimte iets positiefs oplewer.

In Le Clézio se teks is die magsverhoudinge omgekeer. Le Clézio land as 8-jarige seun na die Tweede Wêreldoorlog in Nigerië aan om sy pa te ontmoet, wat deur die oorlog van sy gesin geskei is. Le Clézio, die kind, is van Europese herkoms, en aldus erfgenaam van die kultuur van die koloniseerders van Afrika. Alhoewel die 8-jarige kind nie hiervan bewus is nie, kan die volwasse verteller hierdie feit nie ignoreer wanneer hy sy verblyf in Afrika in oënskou neem nie. Sekere ervarings word uitgesonder, waarvan die belangrikste die anekdote is van Le Clézio (2004:31-34) en sy broer wat termiethope in die veld vernietig. Hy vertel van 'n ongekende gevoel van vryheid na die ingehoktheid van hulle woonstelbestaan tydens die oorlog in Marseille, toe hy en sy broer na die middel van 'n uitgestrekte vlakte hardloop en verwoed met stokke die hoë suile van 'n paar termietneste omslaan. Die terugroep van hierdie insident word sterk deur die digotomie koloniseerder teenoor gekoloniseerde gekodeer. Die verteller skep 'n teenstelling tussen die gesin se huisie en die veld. Die woning word geassosieer met 'alles wat die teken dra van die Britse Ryk' (bl. 27) (sy pa was 'n dokter in die Britse leër) en die vlakte met onbeperkte vryheid. Die volwasse verteller se beskrywing van die afbreek van die miershope beklemtoon die onnodigheid van hierdie verwoede handeling, van hierdie geweld teenoor die blinde termiete. Die verteller interpreteer hierdie gebeurtenis soos volg: 'ons, ons was wild soos jong koloniseerders, seker van ons vryheid, van ons immuniteit, sonder verantwoordelikheid' (bl. 33). Hierdie optrede word gekontrasteer met die houding van die swart kinders waarvan die outeur sê dat hulle hom en sy broer aanvaar het, 'ten spyte van ons verskille' (bl. 29) en dat 'hierdie verwoede vernietiging hulle sou verbaas het, hulle wat in 'n wêreld geleef het waar termiete 'n feit was, waar hulle 'n rol in legendes gespeel het' (bl. 32).

Le Clézio (2004) as skrywer se siening van die interkulturele blyk uit 'n opmerking van die volwasse verteller oor die insident van die afbreek van die termiethope:

$[E] \mathrm{k}$ dink dat dit anders sou verloop het as ons in Ogaja aangebly het, as ons soos die mense van Afrika geword het ... . [E]k sou geleer het om met lewende dinge te praat, om te sien watter goddelike element daar in termiete is. (bl. $34-35)^{31}$

Le Clézio se herbeoordeling van sy eie verlede dui op 'n relativering van sy eie kultuur en van die koloniale bedeling en 'n vorm van respek vir die kultuur van die 'Ander' wat 'n voorwaarde is om die self oop te kan stel vir die 'nie-self'. 'n Etiek van openheid teenoor, en aanvaarding van die 'Ander'

31.j'ai pensé qu'il en aurait été autrement si nous étions restés à Ogaja, si nous étion devenus pareils aux Africains. [...] j'aurais appris à parler avec les êtres vivants, à voir ce qu'il y avait de divin dans les termites'. 
kan uit L'Africain afgelei word: daar is respek vir die 'Ander' wat erken word as 'n gelyke vennoot, terwyl Ken Bugul se Le Boabab fou ([1982] 1996) uitwys hoe kompleks die uitleef van so 'n etiek kan wees.

\section{Slot}

In hierdie oorsig van outobiografieë van Rousseau tot Le Clézio het ons in aansluiting by die teorieë van Gadamer en Ricoeur 'n wye verskeidenheid van uiteenlopende verstaanshandelinge waargeneem: Van die siening van die unieke self wat sonder skroom mag praat; die self wat deur trauma'n deel van homself verloor en deur die skryfhandeling dit weer moet vind; 'n besef van die kompleksiteit van taal as medium vir selfekspressie tot uiteindelik die besef dat die teenwoordigheid van die 'Ander' die uitleg van die self ten diepste bepaal. Voorts is aangetoon hoe die outobiograaf die verstaan van sy of haar lewe op besondere manier in die lig van 'n groter konteks vorm gee. Aangesien hierdie genre ' $n$ besondere plek aan die leser toeken - die 'ek' van die subjek verplig die leser om die posisie van die 'jy' van 'n gespreksituasie in te neem - word die leser ten nouste by die uitleg en beoordeling van die lewenservarings betrek. Op sy beurt moet die leser die outobiografiese teks 'approprieer', sy eie maak, 'n proses waarvan Paul Ricœur ons verseker dat dit selfbegrip bevorder.

\section{Erkenning \\ Mededingende belange}

Die outeur verklaar hiermee dat sy geen finansiële of persoonlike verbintenis het met enige party wat haar nadelig of voordelig kon beïnvloed het in die skryf van hierdie artikel nie.

\section{Literatuurverwysings}

Bhabha, H.K. [1994] 2003, The location of culture, Routledge, London/New York.

Barthes, R., 1975, Roland Barthes par Roland Barthes, Seuil, Paris.

Bugul, K., 1991, The abandoned Baobab: The autobiography of a Senegalese woman, transl. M. de Jager, Lawrence Hill Books, Chicago.

Bugul, K. [1982] 1996, Le Baobab fou, Nouvelles Editions Africaines, Dakar.

Doubrovsky, S., 1977, Fils, Editions Galilée, Paris.

Derrida, J. \& Dufourmantelle, A., 1997, De l'Hospitalité, Calmann-Lévy, Paris.

Eakin, P-J., 1992, Touching the world: Reference in autobiography, Princeton University Press, Princeton. http://dx.doi.org/10.1515/9781400820641

Gadamer, H-G., 1975, Wahrheit und Methode, J.C.B. Mohr, Tübingen.

Gusdorf, G., 1956, 'Conditions et limites de l'autobiographie', in G. Reichenkron \& E. Haase (eds.), Formen der Selbstdarstellung: Analekten zu einer Geschichte des literarischen Selbstporträts, pp. 105-123, Duncker \& Humblot, Berlin.
Gusdorf, G., 1980, 'Conditions and limits of autobiography', in J. Olney (ed.), Autobiography: Essays theoretical and critical, pp. 57-67, University Press Autobiography: Essays theoretical and critical, pp. 57-67, Univers
Princeton, Princeton. http://dx.doi.org/10.1515/9781400856312.28

Hubier, S., 2003, Littératures intimes. Les expressions du moi, de l'autobiographie à l'autofiction, Amand Colin, Paris.

Julien, A-Y., 2002, Marguerite Yourcenar ou la signature de l'arbre, Presses Universitaires de France, Paris.

Kraut, R., 2009, 'The examined life', in S. Ahbel-Rappe \& R. Kamtekar, A companion to Socrates, pp. 228-242, Wiley-Blackwell, Chichester.

Kristeva, J., 1991, Étrangers à nous-mêmes, Gallimard, Paris.

Le Clézio, J-M.G., 2004, L'Africain, Mercure de France, Paris. (Collection Folio).

Le Clézio, J-M.G., 2010, Die Afrikaan, vert. N. Morgan, SUN Press, Bloemfontein.

Lejeune, P., 1971, L'Autobiographie en France, Armand Colin, Paris.

Lejeune, P., 1975, Le Pacte autobiographique, Seuil, Paris.

Lenoir, F. \& Masquelier, Y.T. (eds.), 1997, Encyclopédie des religions, Bayard, Paris.

Levinas, E., 1961, Totalité et Infini. Essai sur l'extériorité, Nijhoff, La Haye.

MacIntyre, A., 1982, After Virtue, Duckworth, London.

May, G., 1979, L'autobiographie, Presses Universitaires de France, Paris.

Olney, J. (ed.), 1980, Autobiography: Essays theoretical and critical, Princeton University Press, Princeton. http://dx.doi.org/10.1515/9781400856312

Perec, G., 1975, W ou le souvenir d'enfance, Gallimard, Paris. (Collection L'Imaginaire). Perec, G., 1988. W, Or the Memory of childhood, transl. D. Bellos, Harvill, London.

Reichenkron, G. \& Haase, E. (eds.), 1956, Formen der Selbstdarstellung: Analekten zu einer Geschichte der literarischen Selbstportraits, Duncker \& Humblot, Berlin.

Ricardou, J., 1971, Pour une théorie du Nouveau roman, Seuil, Paris. (Collection 'Tel Quel').

Ricoeur, P., 1981, Hermeneutics \& the Human Sciences, Cambridge University Press, Cambridge.

Ricœur, P., 1990, Soi-même comme un autre, Seuil, Paris.

Robbe-Grillet, A., 1985, Le miroir qui revient, Editions de Minuit, Paris.

Robbe-Grillet, 1988, Angélique ou l'enchantement, Editions de Minuit, Paris.

Robbe-Grillet, 1994, Les derniers jours de Corinthe, Editions de Minuit, Paris.

Rousseau, J-J., 1952a, Les Confessions, vol. 1, Garnier, Paris.

Rousseau, J-J., 1952b, Les Confessions, vol. 2, Garnier, Paris.

Rousseau, J-J., 1952c, Les Confessions, vol. 3, Garnier, Paris

Sarraute, N., 1956, L'Ėre du soupçon, Gallimard, Paris.

Sarraute, N., 1983, Enfance, Gallimard, Paris.

Sheringham, M., 1993, French autobiography: Devices and desires. Rousseau to Perec, Clarendon Press, Oxford. http://dx.doi.org/10.1093/acprof:oso/9780198158431. 001.0001

Sprinkler, M., 1980, 'Fictions of the self: The end of autobiography', in J. Olney, (ed.), Autobiography: Essays theoretical and critical, pp. 321-342, Princeton, University Press Princeton. http://dx.doi.org/10.1515/9781400856312.321

Weintraub, K.J., 1975, 'Autobiography and historical consciousness', Critical Inquiry 1(4), 821-848. http://dx.doi.org/10.1086/447818

Yourcenar, M., 1974, Souvenirs Pieux, Gallimard, Paris.

Yourcenar, M., 1977, Archives du Nord, Gallimard, Paris.

Yourcenar, M., 1980, Les Yeux Ouverts: Entretiens avec Matthieu Galey, Le Centurion, Paris.

Yourcenar, M., 1981, Discours de réception à l'Académie française, Gallimard, Paris.

Yourcenar, M., 1988, Quoi? L'Éternité, Gallimard, Paris.

Yourcenar, M., 1991a, Essais et Mémoires, Gallimard, Paris. (Éditions de la Pléiade).

Yourcenar, M.,1991b, 'Le Labyrinthe du Monde', in M. Yourcenar, Essais et Mémoires, pp. 705-1433, Gallimard, Paris. (Éditions de la Pléiade).

Yourcenar, M., 1995, How many years, transl. M. L. Ascher, Aidon Ellis Publishing, Henley-on-Thames. 